\title{
Recreating the image of Chan master Huineng: the roles of MOOD and MODALITY

\author{
Hailing Yu ${ }^{*}$ and Canzhong Wu
}

\author{
* Correspondence: \\ hailingyu13@gmail.com \\ Department of Linguistics, \\ Macquarie University, New South \\ Wales 2109, Australia
}

\begin{abstract}
The article investigates the roles of MOOD and MODALITY in the recreation of the image of Chan master Huineng in four English translations of The Platform Sutra by Wong Mou-lam, (Sutra Spoken by the Sixth Patriarch, Wei Lang, on the High Seat of the Gem of Law (Message from the East), 1930), Heng Yin, (The Sixth Patriarch's Dharma Jewel Platform Sutra, 1977), Thomas Cleary, (The Sutra of Hui-neng, grand master of Zen: with Hui-neng's commentary on the Diamond Sutra, 1998) and Cheng Kuan (The Dharmic Treasure Altar-Sutra of the Sixth Patriarch, 2011). MOOD refers to the mood types of indicative and imperative, and MODALITY covers the semantic space between 'yes' and 'no'. Adopting SysFan, a computational tool for doing systemic and functional analysis, the study investigates the choice of mood types and the values of modality (low, median and high) in each translation. Heng and Cleary favour high-valued modality more than Wong and Cheng though the mood type of declarative is adopted by all. They also use more imperative clauses and indicative clauses with high-valued modality than the latter. Consequently, two types of image are recreated of Huineng: an authoritative and forceful Huineng presented by the two American translators, and a prudent and polite Huineng presented by the two Chinese translators. The investigation shows that the phenomenon cannot be accounted for by the translators' linguistic competence. Instead, the context of the translation, especially the tenor, should be taken into consideration to interpret these two types of image of Huineng.
\end{abstract}

Keywords: MOOD, MODALITY, Huineng, Image, Systemic functional linguistics, Context, Tenor

\section{Introduction}

Huineng (638-713) is a great Chan master in the Tang Dynasty of China. He is venerated as the founder of Chinese Chan, Japanese Zen, Korean Sŏn and Vietnamese Thiên (Jorgensen 2005, 1). The source text, The Platform Sutra (1291), is a collection of the public sermons and personal conversations of Huineng and 'one of the best known, most beloved and most widely read of all Chan texts' (Schlutter 2007, 382).

In systemic functional linguistics (SFL), MOOD refers to the mood types of indicative (declarative and interrogative) and imperative, and MODALITY covers the semantic space between 'yes' and 'no' and provides different ways 'in which a language user can intrude on his/her message, expressing attitudes and judgements of various kinds' (Eggins 1994, 179). The role of MOOD and MODALITY in an 
exchange is closely related to the speech functions of the clause, that is, what the speaker is doing through language.

As the basic question of religion is 'how to be and what to do' (Downes 2011, 42), this study focuses on how Huineng provides information and gives commands to his audience and disciples in different translations, and the types of image recreated of him thereby. Direct speeches of Huineng in five chapters from four translations (Wong 1930a, Heng 1977, Cleary 1998, Cheng 2011) are extracted and then analysed in SysFan (Wu 2000), a computational analytical tool for systemic and functional analysis. It is shown that though statements are realized through declarative clauses in all the four translations, there is a significant difference in the certainty/uncertainty of Huineng in the information provided, as illustrated through different values of MODALITY. The realization of commands is more complicated, with a difference in the selection of major mood types (imperative vs. modulated indicative) and values of MODALITY in modulated indicative clauses. Consequently, two types of image recreated of Huineng can be recognized: the authoritative and forceful Huineng presented by the two American translators, Heng Yin and Thomas Cleary, and the prudent and polite Huineng presented by the two Chinese translators, Wong Mou-lam and Cheng Kuan. A possible cause for this is lack of competence in the source language (pre-modern Chinese) on the part of the two American translators. However, as will be explained in this study, linguistic competence cannot account for the phenomenon. The recreating of the two types of image is interpreted from the perspective of the context of translation, especially the tenor between the translator and target readers. Translating for an audience who are not part of their own culture, the two Chinese translators are confronted with greater social distance with the target readers than their American counterparts, who serve either as an information provider for Buddhist practitioners or a cultural mediator bringing in exotic Eastern ideas to ordinary English readers.

The significance of the study lies in its pioneering attempt to apply SFL to the study of translations of The Platform Sutra, an influential text which still has not received enough attention from either SFL or translation studies. Moreover, the study provides an alternative perspective on the research of MODALITY by taking into consideration its close relation to mood types and speech functions. The correlation between text and context, and the interdependence of translation, translator and target readers are also explored through investigation of the mutation of the image of the same person.

Section MOOD and MODALITY: a systemic functional perspective of this study provides a theoretical framework of MOOD and MODALITY based on SFL, which is followed by a description of methodology in section Methodology. Two types of image recreated of Huineng will be discussed in section Result and discussion, and possible textual and contextual factors will be considered in section Why are different types of image recreated. The last section is a conclusion of the whole study.

\section{MOOD and MODALITY: a systemic functional perspective}

Traditionally, MOOD is considered a grammatical category that mainly depends on the form of the verb (Bybee and Suzanne Fleischman 1995, 2) or the status of the clause as Realis and Irrealis (Palmer 2001, 4-5). MODALITY has been studied from the perspectives of semantics (speaker's commitment to the truth value of the proposition) (Lyons 1977, Perkins 1983, Biber et al. 1999, Palmer 2003), pragmatics (Coates 1987, 1990, 
Holmes 1984, Hyland 1994, Myers 1989), and interpersonal interaction (Butler 1988, He 1993, Camiciottoli, Belinda Crawford 2004, Gao 2012, White 2000, 2003).

The combination of MOOD and MODALITY with interpersonal interaction is systematically achieved in SFL, a theory centred on the notion of language function. Three metafunctions of language are recognized in SFL: ideational, interpersonal and textual. The ideational metafunction is to construe people's inner and outer experience of the world, the interpersonal metafunction is for speakers to enact their speech roles and construct relationships with each other, and the textual metafucntion is to create a coherent and understandable text. MOOD and MODALITY are within the interpersonal system and closely related to the speech functions of the clause as proposition and proposal, which is to be demonstrated in the following sections.

\section{Clause as exchange, speech function, MOOD and MODALITY}

Two mood types, indicative and imperative, are recognized in SFL, with each having further sub-classifications, as presented in Fig. 1. The key elements in distinguishing mood types are Subject, a nominal group picked up by the pronoun in the tag question, and Finite element, one of a small number of a verbal operators expressing tense (e.g. is, has) or MODALITY (e.g. can, must).

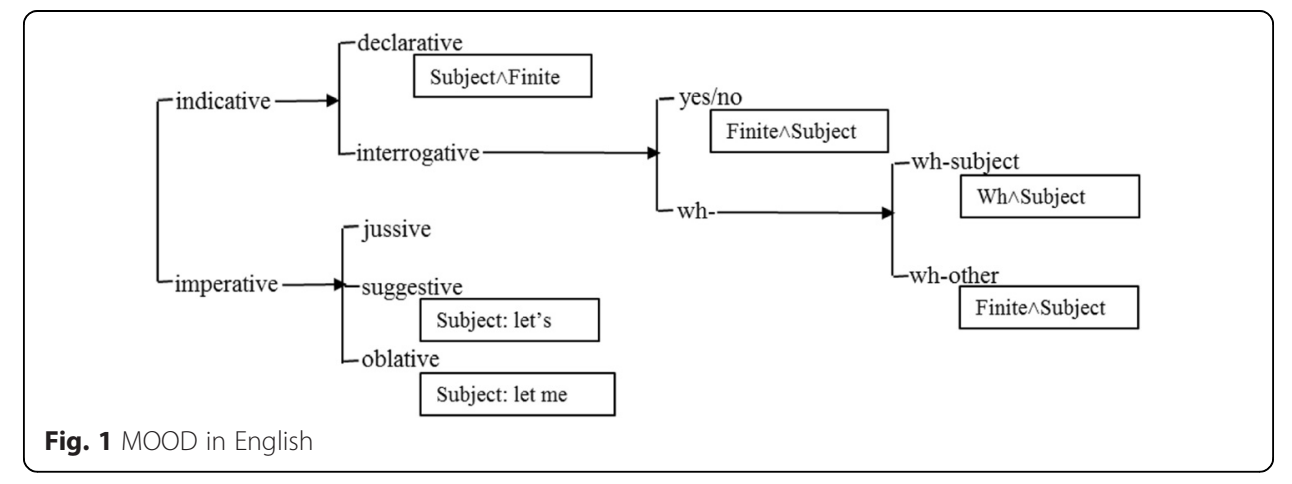

Presence or absence of both the Subject and Finite can be seen as a distinction between indicative and imperative. Within the indicative, the order of the Subject and Finite can serve as a criterion to distinguish 'declarative' (Subject + Finite), 'yes/no interrogative' (Finite + Subject) and 'WH-interrogative' (Subject + Finite if the WH-element is the Subject, and Finite + Subject otherwise) (Halliday and Matthiessen 2004, 111-115).

From an interpersonal perspective, an act of speaking is an act of interaction and the clause functions as an exchange. The speaker can choose either of the two speech roles of giving and demanding, and there are two kinds of things to be exchanged - information and goods and services. Such choices can be realized on the semantic level through speech functions of statement, question, offer and command. Correspondence between speech functions and mood types on the lexico-grammatical level also exists.

As can be seen from Table 1, the mood type of indicative is typically used to exchange information, with declarative as the realization of statement and interrogative as that of question. 'Imperative' is typically chosen to realize commands, and offers may have different kinds of realizations, such as modulated interrogatives. 
Table 1 Clause as exchange

\begin{tabular}{|c|c|c|c|}
\hline commodity & speech role & speech function & \\
\hline \multirow{2}{*}{ information } & giving & $\begin{array}{l}\text { statement } \\
\text { He is an Australian. }\end{array}$ & \multirow{2}{*}{ proposition } \\
\hline & demanding & $\begin{array}{l}\text { question } \\
\text { Is he an Australian? }\end{array}$ & \\
\hline \multirow{2}{*}{ goods-\&-services } & giving & $\begin{array}{l}\text { offer } \\
\text { Would you like a cup of tea? }\end{array}$ & \multirow{2}{*}{ proposal } \\
\hline & demanding & $\begin{array}{l}\text { command } \\
\text { Give me a cup of tea. }\end{array}$ & \\
\hline
\end{tabular}

What are presented in the table are just the congruent, or 'unmarked' ways of realizing the different speech functions, and the status of being 'unmarked' means a high probability of being chosen in conversation. However, it should also be noted that there is no strict one-to-one correspondence between speech functions and mood types (Matthiessen 1995, 438-444), especially in the exchange of goods and services where language is used to achieve non-linguistic ends. It is here MODALITY, in combination with the indicative mood, constitutes an important resource to realize offers (as the example in the table) or commands (such as 'you should give me a cup of tea').

MODALITY is 'a form of participation by the speaker in the speech event' (Halliday 1970, 335) and creates various intermediate degrees between the categorical extremes of unqualified positive and negative. It can be categorized according to the functions of the clause as a proposition or proposal, as illustrated in Table 2 .

Table 2 Speech function and MODALITY

\begin{tabular}{|c|c|c|c|}
\hline \multirow{2}{*}{$\begin{array}{l}\text { Speech function } \\
\text { Proposition }\end{array}$} & \multicolumn{2}{|c|}{ Type of intermediacy } & \multirow{2}{*}{$\begin{array}{l}\text { Example of realization } \\
\text { He may be an Australian. }\end{array}$} \\
\hline & Modalization & Probability & \\
\hline & & & He is possibly an Australian. \\
\hline & & & I think he is an Australian. \\
\hline & & Usuality & He must walk when it is sunny. \\
\hline & & & He always walks when it is sunny. \\
\hline \multirow[t]{4}{*}{ Proposal } & Modulation & Obligation & You should read the book. \\
\hline & & & You are required to read the book. \\
\hline & & Inclination & I will read the book for you. \\
\hline & & & I want to read the book for you. \\
\hline
\end{tabular}

MODALITY in propositions is termed as modalization, and is about how probable or frequent the information is valid. MODALITY in proposals, termed as modulation, is about the obligation and inclination of the interlocutors. MODALITY can be realized in the form of modal auxiliaries, modal adverbs, or separate clauses. Moreover, the value of MODALITY can be graded as low, median or high according to the strength of the assessment. Interpersonally, the more certain the speaker is about the proposition, the more likely he is expecting assent from the hearer; and the higher the value of obligation, the more likely the speaker is expecting the hearer to respond (Croft 1994, 469). A combination of type and value is exhibited in any modal expression, such as those illustrated in Table 3. 
Table 3 Combination of MODALITY type and value

\begin{tabular}{|c|c|c|c|c|}
\hline \multirow[t]{2}{*}{ MODALITY type } & & \multicolumn{3}{|l|}{ Modality value } \\
\hline & & Low & Median & High \\
\hline \multirow[t]{2}{*}{ Modalization } & Probability & $\begin{array}{l}\text { can/could/may/might } \\
\text { possibly, I guess }\end{array}$ & $\begin{array}{l}\text { will/would probably, } \\
\text { I think }\end{array}$ & $\begin{array}{l}\text { must/should certainly, } \\
\text { I know }\end{array}$ \\
\hline & Usuality & $\begin{array}{l}\text { can/could/may/might } \\
\text { sometimes }\end{array}$ & will/would usually & must/should always \\
\hline \multirow[t]{2}{*}{ Modulation } & Obligation & $\begin{array}{l}\text { can/could/may/might } \\
\text { it's permissible... }\end{array}$ & $\begin{array}{l}\text { should/had better, } \\
\text { it's desirable... }\end{array}$ & $\begin{array}{l}\text { must/have to/ought } \\
\text { to it's necessary }\end{array}$ \\
\hline & Inclination & willing to & will/would like to & must/have to \\
\hline
\end{tabular}

The following section will focus on one type of proposition (statement) and one type of proposal (command), and the use of mood and modality in realizing these two speech functions and building a certain image of the speaker.

\section{MOOD and MODALITY in clauses as statements}

In a statement, the speaker provides information. As information is something that can be argued about, the validity of the information becomes the core of an exchange. Moreover, a speaker is not a neutral observer of the world. Whenever one speaks, one is also expressing attitudes, such as certain or uncertain, to the information being conveyed (Coates 1990, 55). The speaker can either say that something IS or IS NOT in a categorical way, or take up an intermediate position between these two poles through the use of MODALITY (therefore the name of 'hedges', (cf. Crompton 1997, Hyland 1996, 1994, Markkanen and Schröder 1997)), as shown in the following two examples.

(1) Huineng is the founder of Chan Buddhism.

(2) Huineng must/would/may be the founder of Chan Buddhism.

From an interactional perspective, the choice of categorical or modalised expressions exhibits the speaker's strategy to orient the hearer towards the validity of the proposition. By uttering example 1, the speaker conveys to the hearer the information that the proposition is valid without any qualification. But in example 2, the definiteness of the proposition is moderated and the focus of the argument is not whether Huineng is or is not the founder, but whether or not he must/would/may be the founder (Butt et al. 2006, 89).

Moreover, such a choice can also reflect the speaker's perception of the potential response from the hearer and help him construct a desirable self-image. Categorical assertions leave no room for dialogue, reject the need for feedback and consign the hearer/reader to a passive role (Hyland 1996, 258). They make the proposition monoglossic (Martin and White 2005, 99-100) and the image of the speaker as being authoritative. On the other hand, modalization can be used to create a heteroglossic environment, to express deference to a superior in conversation (Eggins 1994, 194-195), or to create a less authoritative tenor to balance the power inequality in written texts (ibid, 315). 


\section{MOOD and MODALITY in clauses as commands}

Commands are different from statements. Instead of being usually realized through the congruent mood type, commands are more likely to be realised non-congruently despite having a typical realization of imperative clauses. The reason for this is that the use of imperatives is sometimes restricted and depends on the interpersonal relation between the speaker and the hearer.

(3) You should read The Platform Sutra.

(4) Will you read The Platform Sutra?

(5) Read The Platform Sutra.

Interpersonally, modulated indicative clauses like examples 3 and 4 are 'metaphorical' in comparison with the congruent imperative clause (example 5), and expand the potential for further negotiation. They provide a range of more delicate ways of commanding (Halliday and Matthiessen 2004, 632-633). Instead of the strongly controlling imperative clause 'Read The Platform Sutra', a declarative clause with the modulation of obligation 'should' or an interrogative clause with the modulation of inclination 'will' give more discretion to the hearer who will find it easier to choose to either comply or refuse. Therefore, they are considered a 'politeness' strategy (Brown and Levinson 1987, Butler 1988).

Like modalization in statements, modulation in commands is also an indicator of the speaker's sensitivity to the interpersonal relationship and a way to project his selfimage. Modulated indicative clauses are typically used to reflect deference and the image of the speaker will therefore be more polite compared with imperatives.

The interpersonal function of MOOD and MODALITY provides an important resource for speakers to build a desirable image for themselves and the perception of the image of a certain person on the part of the hearer. Simpson (1990, 64), for example, points out that the adoption of modulated indicative clauses to realize commands can not only help maintain the social relationship, but also lead to a favourable evaluation of the 'personality' of the writer/speaker by the addressee. Politicians tend to use MODALITY in statements during media interviews to construct an image of confidence and intelligence for themselves (Simon-Vandenbergen 1996).

\section{Methodology}

Data

The four English translations constituting the data of this study are presented in Table 4.

The criterion of selection is heterogeneity in terms of translator's identity, publishing time and agency. Both Chinese and American translators are included in this study. Translators from the same cultural background are further distinguished by their religious identity, either as a layperson (one who is not ordained to Buddhism), or as a Buddhist. Time gaps between the different translations also exist, with the first one produced in 1930 and the last one in 2011. As for publishing agencies, all of the translations are published by institutions affiliated to Buddhist institutions with the exception of the translation of Thomas Cleary, which is published by Shambhala Publications. This heterogeneity is assumed to be likely to lead to variation in linguistic choices and the types of image of Huineng. 
Table 4 Four English translations chosen in the study

\begin{tabular}{|c|c|c|c|c|}
\hline Translator & Title of translation & Translator's identity & Publishing year & $\begin{array}{l}\text { Publishing agency } \\
\text { and place }\end{array}$ \\
\hline Wong Mou-lam & $\begin{array}{l}\text { Sutra Spoken by the } \\
\text { Sixth Patriarch (Wei Lang) } \\
\text { on the High Seat of The } \\
\text { Gem of Law (Message } \\
\text { from the East) }\end{array}$ & Chinese, layperson & 1930 & $\begin{array}{l}\text { The Pure Karma } \\
\text { Buddhist Association, } \\
\text { Shanghai }\end{array}$ \\
\hline Heng Yin & $\begin{array}{l}\text { The Sixth Patriarch's } \\
\text { Dharma Jewel Platform } \\
\text { Sutra }\end{array}$ & American, Buddhist & $\begin{array}{l}1977 \text { (second } \\
\text { edition) }\end{array}$ & $\begin{array}{l}\text { The Buddhist Text } \\
\text { Translation Society, } \\
\text { San Francisco }\end{array}$ \\
\hline Thomas Cleary & $\begin{array}{l}\text { The Sutra of Hui-neng, } \\
\text { Grand Master of Zen - with } \\
\text { Hui-neng's Commentary on } \\
\text { the Diamond Sutra }\end{array}$ & American, layperson & 1998 & $\begin{array}{l}\text { Shambhala } \\
\text { Publications, USA }\end{array}$ \\
\hline Cheng Kuan & $\begin{array}{l}\text { The Dharmic Treasure } \\
\text { Altar-Sutra of the Sixth } \\
\text { Patriarch }\end{array}$ & Chinese, Buddhist & $\begin{array}{l}2011 \text { (second } \\
\text { edition) }\end{array}$ & $\begin{array}{l}\text { Neo-Carefree Garden } \\
\text { Buddhist Canon } \\
\text { Translation Institute, } \\
\text { Taipei }\end{array}$ \\
\hline
\end{tabular}

Direct speeches of Huineng in five chapters, Chapter Two, Four, Five, Six and Seven are extracted from each translation as the data of analysis in this study. These chapters comprise both Huineng's public sermons and conversations with disciples.

\section{Procedure}

The extracted direct speeches of Huineng are divided into clauses and imported into SysFan, a computational tool to produce systemic and functional analysis (Wu 2000). A total of 4836 clauses from the four translations are analysed according to the lexico-grammtical realization of the interpersonal system of English, which is illustrated in Fig. 2. Result can be summarized automatically and MOOD and MODALITY of all clauses can be retrieved after the analysis.

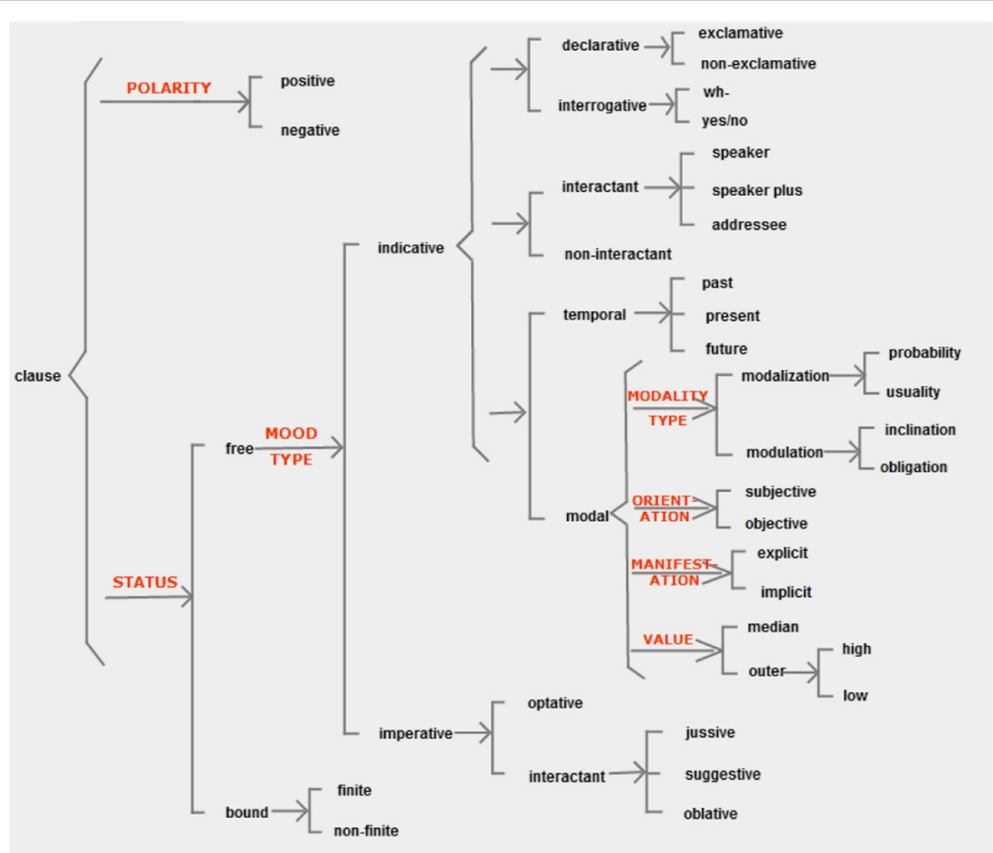

Fig. 2 Interpersonal system of English in SysFan 
As for the presentation of the analysis result, there are two points that need explication. Firstly, for clauses as statements, analysis result of both the declarative and bound finite (dependent) clauses will be listed. Since the study takes the clause as the unit of analysis, in cases where more than one modal expression of probability or usuality occurs in the same clause, only the one with higher value will be counted. For example, in the following clauses, both modal auxiliaries and adverbs are used in the same clause. The whole clause is counted as modalised and only the expression with a higher value (surely and always) will be exhibited in the analysis result.

(6) Those who never regress all their lives will surely enter the ranks of sages (Cleary, Chapter 2).

(7) Thus, they would always unfold the Apprehension-Perception of Plebeians for themselves (Cheng, Chapter 7).

Secondly, for clauses as commands, only imperatives and free modulated indicatives will be included, as dependent clauses with modulations such as the following example cannot serve as command for others to do something.

(8) The Words in the Sutra profess distinctly that you should 'take Refuge under Buddha intrinsically (Cheng, Chapter 6).

Modulated clauses with inclusive 'we' as subjects (only appear in Wong Mou-lam's translation) are regarded as realizing commands in this study, as shown in example 9. This kind of realization is considered a strategy by the speaker to shorten the distance between himself and the hearer, and is therefore more polite and less threatening than clauses containing 'you' as subjects.

(9) Within, we should control our mind; without, we should be respectful towards others (Wong, Chapter 6).

Free modulated clauses with non-interactant third person subjects, though may be regarded as intermediate between propositions and proposals (Halliday and Matthiessen 2004,148 ) (such as John should do that), are regarded as commands in our analysis. The reason lies in the fact that in our data, though the subjects of these clauses take the form of third person, they are usually generalized and have the potential to be applied to the audience, such as example 10, or clearly refer to the audience, such as example 11, thus have the function of commands.

(10) Those who are under delusion have to train themselves gradually (Wong, Chapter 4).

(11) Both laity and monks should put its teaching into practice (Wong, Chapter 2).

As modal auxiliaries are notoriously polysemic, there are inevitably some cases where the meaning of a modal auxiliary is hard to identify. A solution of referring to the source text, comparing with other translations and examining the co-text is taken in order to pin down the exact meaning and make the analysis reliable. 


\section{Result and discussion}

\section{Statements: how authoritative is Huineng?}

Analysis shows that when providing information to the audience, Huineng uses declarative clauses in all the translations. Significant difference lies in the certainty/uncertainty of what he is saying, which is illustrated in Table 5 in terms of numbers and frequencies of clauses without and with MODALITY. While clauses containing MODALITY reach 31 and $15 \%$ in translations by Cheng and Wong, only 7 and $9 \%$ of the clauses are qualified in Cleary's and Heng's translations. Moreover, values of MODALITY also differ among these translations, with 38 and $19 \%$ modal expressions being high valued in translations of Cleary and Heng, in comparison to the much lower frequencies in Wong (11\%) and Cheng (8\%).

Table 5 MODALITY in clauses as statements

\begin{tabular}{|c|c|c|c|c|c|}
\hline & & Wong & Heng & Cleary & Cheng \\
\hline \multicolumn{2}{|c|}{ Clauses without MODALITY } & $703(85 \%)$ & 781 (91\%) & $860(93 \%)$ & $643(69 \%)$ \\
\hline \multicolumn{2}{|c|}{ Clauses with MODALITY } & $129(15 \%)$ & 74 (9 \%) & $63(7 \%)$ & $286(31 \%)$ \\
\hline \multicolumn{2}{|l|}{ Low value } & $42(32 \%)$ & $12(16 \%)$ & $10(16 \%)$ & $44(15 \%)$ \\
\hline & can & 8 & - & 2 & 14 \\
\hline & could & - & - & - & 17 \\
\hline & may & 33 & 9 & 8 & 11 \\
\hline & might & 1 & 3 & - & 2 \\
\hline & I gather & - & - & - & - \\
\hline \multicolumn{2}{|l|}{ Median value } & $73(57 \%)$ & $48(65 \%)$ & $29(46 \%)$ & $220(77 \%)$ \\
\hline & will(not) & 38 & 41 & 23 & 45 \\
\hline & shall(not) & 5 & 1 & - & 19 \\
\hline & would(not) & 30 & 6 & 6 & 156 \\
\hline \multirow[t]{7}{*}{ High value } & & $14(11 \%)$ & $14(19 \%)$ & $24(38 \%)$ & $22(8 \%)$ \\
\hline & cannot & 3 & 2 & - & 1 \\
\hline & must & 2 & 1 & 1 & 1 \\
\hline & certainly & - & - & 1 & - \\
\hline & surely & - & - & 2 & - \\
\hline & always & 5 & 6 & 14 & 11 \\
\hline & never & 4 & 5 & 6 & 9 \\
\hline \multicolumn{2}{|l|}{ Total clauses } & 832 & 855 & 923 & 929 \\
\hline
\end{tabular}

This provides strong interpersonal indications. In The Platform Sutra, Huineng is either preaching on the principles of Chan Buddhism or answering his disciples' questions. Uncertainty due to lack of knowledge is almost ruled out by the context and an interpersonal consideration seems more plausible. High frequencies of unqualified clauses and high-valued MODALITY in Cleary's and Heng's translations help the translators recreate an authoritative image for Huineng who intends to regard all his words as definite and indisputable. In comparison, Cheng and Wong, by qualifying many of the statements through median- and low-valued MODALITY, recreate the image of Huineng as cautious and less threatening. Examples are presented in the following. 
Unqualified vs. qualified statements

Example 1

\begin{tabular}{ll}
\hline ST: & kou nian xin bu xing ru huan ru hua ru ru dian kou nian xin xing ze xin kou xiangying (Chapter 2) \\
Cleary: & Verbal repetition without mental application is illusory and evanescent. When it is both spoken \\
& of and mentally applied, then mind and speech correspond. \\
Heng: & When the mouth recites and the mind does not practice, it is like an illusion, a transformation, \\
& dew drops, or lightning. However, when the mouth recites and the mind practices, then mind \\
& and mouth are in mutual accord. \\
Wong: & Mere reciting it without mental practice may be likened to a phantasm, a magical delusion, \\
& a flash of lightning or a dewdrop. On the other hand, if we do both, then our mind would be \\
& in accord with what we repeat orally. \\
Cheng: & If it is merely muttered in the mouth without Mental Implementations, it would be like Phantasm \\
& or Metamorphosis, or like dew drops and electricity. Chanting verbally and implementing mentally \\
& at the same time could make both the mouth and the Mind congruently corresponding.
\end{tabular}

In this example, Huineng is comparing two ways of practicing Chan, verbal reciting only and a combination of verbal reciting and mental practice, by pointing out the futility of the former and the productivity of the latter. Both Cleary and Heng translate the sentences into categorical statements, showing that Huineng is absolutely certain in making judgement of the two kinds of practice. In comparison, Huineng in the translations by Wong and Cheng is more cautious as he says that there may/would be such an analogy between verbal reciting only and certain things, and the combination of verbal and mental practice would/could lead to a certain consequence.

\section{Example 2}

\begin{tabular}{|c|c|}
\hline ST: & $\begin{array}{l}\text { shan zhi shi ding hui you ru he deng you ru dengguang youdeng ji guang wu deng ji an } \\
\text { 善知识定慧犹如何等 犹如灯 光 有灯即 光 无灯即闇 (Chapter 4) }\end{array}$ \\
\hline Cleary: & $\begin{array}{l}\text { Good friends, what are stabilization and insight like? They are like a lamp and its light. If there is a } \\
\text { lamp, there is light; without a lamp, there is darkness. }\end{array}$ \\
\hline Heng: & $\begin{array}{l}\text { Good Knowing Advisors, what are concentration and wisdom like? They are like a lamp and its light. } \\
\text { With the lamp, there is light. Without the lamp, there is darkness. }\end{array}$ \\
\hline Wong: & $\begin{array}{l}\text { Learned Audience, what are Samadhi and Prajna analogous to? They may be analogous to a lamp and } \\
\text { its light. With the lamp, there is light. Without it, it would be dark. }\end{array}$ \\
\hline Cheng: & $\begin{array}{l}\text { Good Mentors, what is Stasis-Wisdom like? It can be likened to the Lamp and the Light: If there is a } \\
\text { Lamp, there would be Light; if there is no Lamp at all, it would be only pitch-dark. }\end{array}$ \\
\hline
\end{tabular}

This example is taken from Chapter 4 where Huineng is giving a definition to Samadhi and Prajna. Being an illustration of the resistance to absolutism and consideration of the audience's understanding, definition through analogy is characteristic of Huineng's teaching (Yu 2011, 65). It is interesting to see how Cleary and Heng present the analogy as definite and Wong and Cheng interpret this with low-valued modality 'may' and 'can'. The causal relationship between lamp and light/darkness is also put in different ways, being either unequivocal or merely hypothetical through the use of 'would' (Coates 1983, 211). 
Example 3

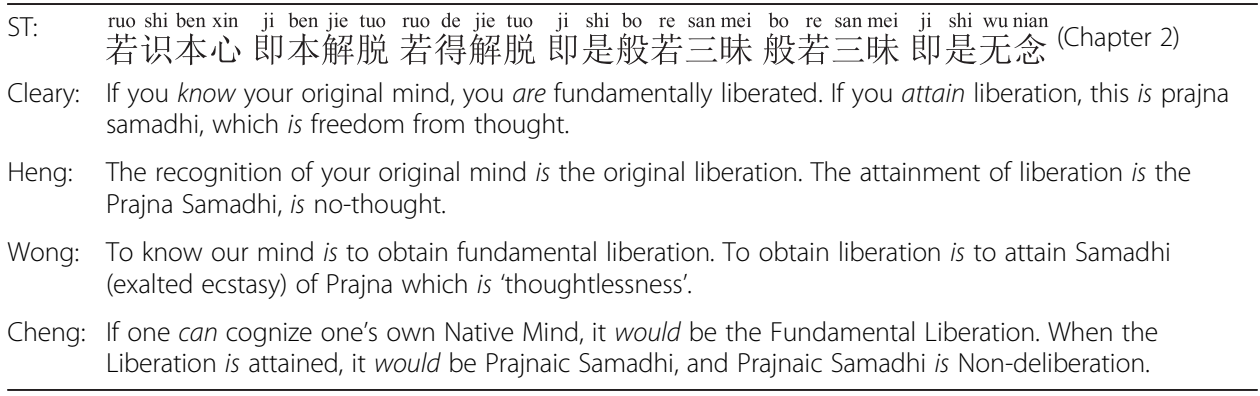

This example is an illustration of the tendency to use more qualified clauses by Cheng in comparison with the other three translators. As can be seen from Table 4, the highly frequent use of 'would' in Cheng's translation contributes to its high frequency of qualified statements. Preference to this word makes the text sound academic and the image of Huineng scholarly as if talking about philosophical hypotheses.

Median- and low-valued vs. high-valued modalization

Example 4

\begin{tabular}{ll}
\hline ST: & ru shen de wu sheng zhi yi (Chapter 7) \\
Cleary: & 汝甚得无 生之意 \\
Heng: & You have certainly gotten the intent of nonconception! \\
Cheng: & You have truly got the idea of nonproduction. \\
\hline
\end{tabular}

This example is taken from Huineng's conversation with one of the disciples who came afar to consult him. After talking with the disciple, Huineng makes a comment on his understanding of the Buddhist principle. While Huineng evaluates the nature (truly) and manner (well) of the student's understanding in translations by Heng and Cheng, he expresses his assessment of the probability with a high-valued modality (certainly) in Cleary' translation. Wong's translation is missing from the example as this is translated into an indirect speech (The Patriarch then commended him for his thorough grasp of the motion of 'Birthlessness'), which is not included in our data.

\section{Commands: how powerful is Huineng?}

There is also significant difference among the four translations in the realization of commands, as shown in Table 6. Cleary and Heng apparently favour imperatives much more than Wong and Chen, using 70 and $68 \%$ imperative clauses in their translations respectively. On the contrary, Cheng uses only $32 \%$ imperative clauses in expressing commands. Imperatives and indicative clauses containing MODALITY occupy almost equal statuses in Wong's translation, but a more polite form of imperative, suggestive (Let's/Let us), is adopted by Wong. Different from a jussive imperative, where the hearer 'you' is the only 
one responsible to carry out the action, a suggestive clause assigns the proposal to both the hearer and the speaker and can be seen as an intermediate between an offer and a command (Matthiessen 1995, 423, 425). In this way the command is softened and the image of the speaker also becomes more considerate.

Table 6 Realization of commands

\begin{tabular}{|c|c|c|c|c|c|}
\hline & & Wong & Heng & Cleary & Cheng \\
\hline \multirow[t]{3}{*}{ Imperatives } & & $58(50 \%)$ & $117(68 \%)$ & $86(70 \%)$ & $33(32 \%)$ \\
\hline & jussive & $42(72 \%)$ & $117(100 \%)$ & $86(100 \%)$ & $33(100 \%)$ \\
\hline & suggestive & $16(28 \%)$ & - & - & - \\
\hline \multicolumn{2}{|c|}{ Modulated indicatives } & $59(50 \%)$ & $55(32 \%)$ & $36(30 \%)$ & 70 (68 \%) \\
\hline \multicolumn{2}{|l|}{ Total clauses } & 117 & 172 & 122 & 103 \\
\hline
\end{tabular}

In demanding the hearer to take an action, imperative clauses are considered the most direct and bald way (Brown and Levinson 1987, 69). Although potentially fact-threatening and usually avoided, imperative clauses can be viewed as an indication of the powerful status of the speaker over the hearer when actually used, especially in comparison with the modulated indicative form such as 'You should...'(Eggins and Slade 1997, 88). Interpersonally, modulated clauses are less imposing as they ground the demand in the subjectivity of the speaker and make allowance for alternatives.

Therefore, by relying more on imperative clauses to issue commands, Huineng in the translations by Cleary and Heng appears to be more direct and powerful than the same Chan master presented by Wong and Cheng. This is further illustrated through the frequency of high-valued against median- and low-valued modulation in indicative clauses, as shown in Table 7.

Table 7 MODALITY in indicative clauses as commands

\begin{tabular}{|c|c|c|c|c|c|}
\hline & & Wong & Heng & Cleary & Cheng \\
\hline Modulated indicatives & & 59 & 55 & 36 & 70 \\
\hline \multirow[t]{5}{*}{ Low value } & & $4(7 \%)$ & $2(4 \%)$ & $1(3 \%)$ & $8(11.5 \%)$ \\
\hline & need not & 4 & 1 & - & 1 \\
\hline & may & - & 1 & - & 3 \\
\hline & can & - & - & 1 & 3 \\
\hline & could & - & - & - & 1 \\
\hline \multirow[t]{4}{*}{ Median value } & & $49(83 \%)$ & $39(71 \%)$ & $28(78 \%)$ & $54(77 \%)$ \\
\hline & will & 2 & - & - & - \\
\hline & should & 46 & 39 & 28 & 53 \\
\hline & shall & 1 & - & - & 1 \\
\hline \multirow[t]{5}{*}{ High value } & & $6(10 \%)$ & $14(25 \%)$ & 7 (19 \%) & $8(11.5 \%)$ \\
\hline & have to & 5 & - & - & - \\
\hline & must & - & 13 & 4 & - \\
\hline & ought to & 1 & 1 & - & 2 \\
\hline & need to & - & - & 3 & 6 \\
\hline
\end{tabular}


As shown in the table, Heng and Cleary use fewer modulated clauses, but there is a higher frequency of high-valued modulation in their translations (25 and $19 \%$ respectively) than the other two (11.5 in Cheng and $10 \%$ in Wong). As values of modulation is a reflection of the strength of the modal assessment, the higher the value, the stronger the command, and the more power the speaker assumes for himself over the hearer.

Examples illustrating difference in realizing commands through two kinds of mood types and variation in the values of modulation are provided in the following.

Imperative clauses vs. modulated indicative clauses

Example 5

\begin{tabular}{ll}
\hline ST: & bi you he yan ju ru shi ju kan (Chapter 7) \\
Cleary: & 彼有何言句 汝试举看 \\
Heng: & What did he have to say? Try to quote him. \\
Wong: & What instruction did he give you? Try to repeat it to me. \\
Cheng: & What instruction did he give you? Will you please repeat it? \\
\hline
\end{tabular}

This example is taken from Huineng's conversation with a disciple who says that he failed to understand the words of another master he visited before. Huineng then asks the disciple to repeat what the other master has said. Both Cleary and Heng translate the second clause into imperative, while modulated indicative clauses are used by Wong and Cheng. In Wong's translation, Huineng uses 'will' to inquire the inclination of the student to carry out the action. In Cheng's translation, instead of expressing obligation, Huineng grants permission to the student by saying 'you can...'. Both these forms are indirect in giving orders and exhibit Huineng's effort to balance the inequality between a teacher and a student.

\section{Example 6}

\begin{tabular}{ll}
\hline ST: & jin ke ge ge hu gui \\
Cleary: & 今可各各胡跪 (Chapter 6) \\
Heng: & Now let each of you kneel. \\
Wong: & Now all of you kneel. \\
Cheng: & Now let us kneel down in the Indian fashion. \\
\hline
\end{tabular}

In this example, Huineng is asking a large audience to kneel down before leading them to perform the ritual of repentance. Both Cleary and Heng use 'marked' imperatives (cf. Halliday and Matthiessen 2004, 138) with explicit subjects (each of you and all of you) to emphasize the audience as responsible to carry out the action. Wong, though also uses an imperative, creates a relatively more intimate tone by using a suggestive 'let us', 
despite that Huineng does not actually do the action together with his audience (Wong 1930a, 29). Cheng still uses 'can' to express the order in the form of a permission, with the result of creating a rather undemanding image for Huineng.

Median- and low-valued vs. high-valued modulation in indicative clauses

Example 7

\begin{tabular}{|c|c|}
\hline ST: & $\begin{array}{l}\text { shan zhi shi ruo yu ru shenshen fa jie ji bo re san mei zhe xu xiu bo re xing } \\
\text { 善知识若欲入甚深法界及般若三昧者须修般若行 (Chapter 2) }\end{array}$ \\
\hline Cleary: & $\begin{array}{l}\text { Good friends, if you want to enter the most profound realm of reality and prajna samadhi, } \\
\text { you should cultivate the practice of prajna. }\end{array}$ \\
\hline Heng: & $\begin{array}{l}\text { Good Knowing Advisors, if you wish to enter the extremely deep Dharma realm and the } \\
\text { Prajna samadhi, you must cultivate the practice of Prajna. }\end{array}$ \\
\hline Wong: & $\begin{array}{l}\text { Learned Audience, if you wish to penetrate the deepest mystery of the Dharmadhatu } \\
\text { (the sphere of the law) and the Samadhi of Prajna, you should practice Prajna... }\end{array}$ \\
\hline Cheng: & $\begin{array}{l}\text { Good Mentors, those who desire to enter into the profound Dharmic Sphere and Prajnaic Samadhi, } \\
\text { should cultivate on the Prajnaic Deed. }\end{array}$ \\
\hline
\end{tabular}

This example illustrates that though all translators may use modulated indicative clauses to realize commands, difference still exists in the force of the commands exhibited through values of the modulation. It can be seen that Heng is the only one to use a high-valued 'must'. All the other three translators choose a less threatening 'should' with a median value.

\section{Example 8}

\begin{tabular}{ll}
\hline ST: & $\begin{array}{l}\text { yu nu hua ta ren zi xu youfangbian } \\
\text { 欲拟化他人自须有方便 }\end{array}$ \\
Cleary: & If you want to try to teach other people, you need to have expedient methods yourself. \\
Heng: & If you hope and intend to transform others, you must perfect expedient means. \\
Wong: & $\begin{array}{l}\text { Those who intend to be the teachers of others should themselves be skilled in the various } \\
\text { expedients which lead others to enlightenment. }\end{array}$ \\
Cheng: & With a view to edifying other people, you should be equipped with Expedient Dexterities.
\end{tabular}

This example is taken from the verse at the end of Chapter 2 where Huineng summarizes what he has preached in the whole chapter. It can be seen that high-valued modal expressions (need to and must) are used by the two American translators, Cleary and Heng, while a median-valued 'should' is used by the two Chinese translators Wong and Cheng. Wong's translation, though has a third-person subject, is still counted as a command, as the pronoun 'those' here is usually generalized and can be interpreted by the hearer as including himself.

\section{Summary}

As can be seen from the previous discussions, in providing information through statements, Heng and Cleary favour categorical clauses (clauses without MODALITY), and 
high-valued modalization more than Wong and Cheng. Similarly, they use more imperatives and high-valued modulation than Wong and Cheng in realizing commands.

Therefore, the four translations can be generally classified into two groups: those by the two western translators Heng and Cleary and those by the two Chinese translators Wong and Cheng. Consequently, there are roughly two types of image recreated of Huineng in the four translations, one being authoritative and powerful, and the other being modest and polite.

This identification of two types of Huineng's image and classification of the translators into two groups highlight the possible influence of the linguistic and cultural background of the translators. It appears that the religious identities of the translators (layperson or Buddhist) and time gaps between the translations fail to make any impact.

A consideration of the two different cultures, moreover, seems to run contrary to the finding. Patriarchal tradition and granting teachers with absolute authority and power are apparently more acceptable and prevalent in Chinese than American culture. Then, is it possible that the two Chinese translators, being relatively more familiar with the source language, have the ability to capture linguistic subtleties which are neglected by the two American translators? Or, if this source language competence hypothesis cannot be supported, is it possible that the reason may lie in the context rather than the text?

\section{Why are different types of image recreated?}

The question can be answered from two perspectives, the perspective of text and that of context. The first part in this section will focus on the possible textual constraints that may have been neglected by the two American translators but captured by the two Chinese translators. The second part will move on to contextual considerations with emphasis on the social distance between the translators and target readers.

\section{Textual consideration}

In realizing statements, difference among translations lies in the choice of categorical vs. qualified clauses. As the two American translators tend to produce categorical expressions and the two Chinese translators tend to moderate the clauses through MODALITY, are there linguistic elements of uncertainty that elude the attention of the American translators but captured by their Chinese counterparts?

The answer is roughly 'No'. Different from English where MODALITY is realized both grammatically in the form of modal auxiliaries within the Finite of the clause (Halliday and Matthiessen 2004, 115-116) and lexically in the form of modal adverbs and separate clausal expressions, MODALITY in Chinese is lexicalized (Halliday and Edward McDonald 2004, 339) as Chinese does not have corresponding finiteness (Matthiessen and Halliday 2009, 10). Therefore it is relatively easy to detect modal expressions in Chinese.

In the source text, lexical expressions of (un)certainty are rarely adopted in statements. Where there does exist such an expression, it tends to be captured by all the translators. 
Example 9

\begin{tabular}{ll}
\hline ST: & ru xin zhong bi you yi wu \\
& 汝心 中 必有一物 (Chapter 7) \\
Cleary: & You must have something on your mind. \\
Heng: & There must be something on your mind. \\
Wong: & There must be something in your mind that makes you so puffed up. \\
Cheng: & You must be harbouring something in your mind. \\
\hline
\end{tabular}

It can be seen that the expression of subjective assessment of certainty on the part of the speaker through the lexical item “必 of a modal auxiliary 'must' in all the translation.

But as can be illustrated in the following two examples, which are repetitions of the previous Example 1 and 2 with only the modalised translations by Wong and Cheng, in many cases the two Chinese translators choose to modify the statements which do not have corresponding features in the source text.

\section{Example 10}

\begin{tabular}{|c|c|}
\hline ST: & $\begin{array}{l}\text { kou nian xin bu xing ru huan ru hua ru lu ru dian kou nian xin xing ze xin kou xiangying } \\
\text { 口念心不行如幻如化 如露如电口念心行则心口相应 }\end{array}$ \\
\hline Wong: & $\begin{array}{l}\text { Mere reciting it without mental practice may be likened to a phantasm, a magical delusion, } \\
\text { a flash of lightning or a dewdrop. On the other hand, if we do both, then our mind would } \\
\text { be in accord with what we repeat orally. }\end{array}$ \\
\hline Cheng: & $\begin{array}{l}\text { If it is merely muttered in the mouth without Mental Implementations, it would be like } \\
\text { Phantasm or Metamorphosis, or like dew drops and electricity. Chanting verbally and implementing } \\
\text { mentally at the same time could make both the mouth and the Mind congruently corresponding. }\end{array}$ \\
\hline
\end{tabular}

\section{Example 11}

\begin{tabular}{|c|c|}
\hline ST: & $\begin{array}{l}\text { shan zhi shi ding hui you ru he deng you ru dengguang youdeng ji guang wu deng ji an } \\
\text { 善知识定慧犹如何等 犹如灯 光 有灯即 光 无灯即闇(Chapter 4) }\end{array}$ \\
\hline Wong: & $\begin{array}{l}\text { Learned Audience, what are Samadhi and Prajna analogous to? They may be analogous to a } \\
\text { lamp and its light. With the lamp, there is light. Without it, it would be dark. }\end{array}$ \\
\hline Cheng: & $\begin{array}{l}\text { Good Mentors, what is Stasis-Wisdom like? It can be likened to the Lamp and the Light: If there } \\
\text { is a Lamp, there would be Light; if there is no Lamp at all, it would be only pitch-dark. }\end{array}$ \\
\hline
\end{tabular}

Similarly, in realizing commands, where the source text has explicit modulating expressions, they tend to be retained in all the translations. 
Example 12

\begin{tabular}{|c|c|}
\hline ST: & $\begin{array}{l}\text { dangyong da zhi hui da po wu yun fan nao chen lao } \\
\text { 当用大智慧打破五蕴烦恼尘劳 (Chapter 2) }\end{array}$ \\
\hline Cleary: & You should use great wisdom to break through the afflictions and mundane toils of the five clusters. \\
\hline Heng: & You should use great wisdom to destroy affliction, defilement, and the five skandhic heaps. \\
\hline Wong: & We should use this great wisdom to break up the five Skandhas... \\
\hline Cheng: & $\begin{array}{l}\text { One should implement great Wisdom to crash the Annoyances derived from the Penta-Aggregates, } \\
\text { as well as the Mental Toils of Worldly Cares. }\end{array}$ \\
\hline
\end{tabular}

In this example, the lexical item “当, which is an expression of obligation in the source text, is translated into its corresponding modulation 'should' in English by all the translators.

Yet the tendency to change the original imperative clauses into modulated indicative clauses by the two Chinese translators is apparent, as can be seen in the following example.

Example 13

\begin{tabular}{ll}
\hline ST: & bi you he yan ju ru shi ju kan \\
Wong: & 彼有何言句 汝试举看 \\
Cheng: & What instruction did he give you? Will you please repeat it? \\
\hline
\end{tabular}

Therefore, it seems that the linguistic competence hypothesis is refuted by the fact that in many cases, the two Chinese translators choose to soften the statements/commands where no source text constraints can be found. Then what is the possible reason? To answer this question, a broader picture needs to be drawn and the context of translation needs to be considered.

\section{Contextual consideration}

A text cannot be separated from its context. The relation between text and context is dynamic in that context is realized in text and text can reveal context (Butt et al. 2006, 182). Context of situation (or register), which is the immediate environment of the text, can be described in three dimensions: field (what is to be talked or written about), tenor (the relationship between the speaker/writer and hearer/reader) and mode (the kind of text that is being made) (ibid, 5).

Our focus here will be on tenor between the translator and target readers, as MOOD and MODALITY are within the interpersonal system of language and a reflection of Tenor. One variable of Tenor: social distance (Butt 2004, Halliday and Hasan 1989) will be mainly investigated. Social distance in translation refers to 'the amount of shared contextual space which the participants are assigned' (Steiner 1998, 294), that is, the frequency of previous interaction and the degree of sharing the same culture and codes. 
It is assumed that the social distance of the translator with target readers will have an influence on his linguistic choices and the type of image of Huineng recreated in the translation.

Wong Mou-lam is the first one to translate The Platform Sutra into English. He was born in Hong Kong and came to Shanghai in his twenties. In 1928, he was requested by Dih Ping Tsze, one of the founders of the Pure Karma Buddhist Association, to translate the sutra into English. One and half year later, the translation was published by the association and copies were taken to London and soon sold out (Ko 1996, 910). The purpose of translation is to make the ideas of Chan Buddhism known to the Westerners and the targeted readers are Westerners with an interest in this Eastern religion (Dih 1930, Wong 1930b). The social distance between the translator and the target readers is therefore near maximal as a clear division of 'they' as 'the Europeans and Americans' and 'we' as 'people of the East' can be seen in Dih's preface and the translator himself kept apologizing to the target readers for his incompetence in providing a good translation.

Formerly an English major in college and a translator after graduation, Cheng Kuan was ordained in 1988 and now is the founder and abbot of two temples, one in Taiwan (Maha-Vairocana Temple, 1991) and the other in America (Americana Buddhist Temple, 1993). From 2005 he began translating Chinese Buddhist texts into English and up to now he has translated six books. All these translations are published by the publishing institutions under his charge and distributed for free. Although Cheng Kuan has a temple in America, most of his disciples are American Chinese, which can be seen from the name list of donors contributing to the translation of The Platform Sutra, where only three Westerners can be recognized among his 350 disciples (Cheng 2011, 273-276). Therefore, it can be assumed that there is actually still social distance between the translator and his targeted American readers. On the other hand, the fact that the translator has the experience of living in America for more than twenty years (Low 2010, 36) may have helped him become more aware of the cultural and ideological difference confronted in the process of translating a typical Eastern religious text into English.

By contrast, both Heng Yin and Thomas Cleary are native-born Americans. Heng Yin is the first Westerner and ordained Buddhist to translate The Platform Sutra into English. Her translation of the sutra is accompanied by the commentary of Hsuan Hua, who was also Heng Yin's teacher. The aim of translating the sutra, according to Hsuan Hua's introduction, is to help the Westerners to 'realize Bodhi and accomplish the Buddha way' (Hsuan 1977, xvi). The target readers are Western Buddhist practitioners. It can be estimated that the social distance between Heng Yin and her target readers is nearly minimal.

The same applies to Thomas Cleary, who is a professional translator of East Asian culture and philosophy, and one of the major authors of Shambhala Publications. Judged by the title (Sutra of Huineng), publishing agency and introduction to the translation, the target readers of the translation should be ordinary English readers who may be interested in the story and ideas of Huineng who is described as 'perhaps the most respected and beloved figure in Zen Buddhism' (from the blurb of the translation). Being a translator of more than 80 works on Eastern religions and philosophy, Cleary plays the role of a cultural mediator introducing Eastern ideas to his fellow Americans. The social distance between him and the target readers is therefore also minimal. 
Translating for an audience who are not part of their own culture, Wong Mou-lam and Cheng Kuan are confronted with a huge social distance in between. The awareness of the possibility that the target readers may find the exotic Chan Buddhist ideas hard to accept probably contributes to the presentation of Huineng as cautious in making statements and polite in issuing commands. On the other hand, the idea of translating for readers sharing the same language and culture can explain why Heng Yin and Thomas Cleary do not consider it important to qualify Huineng's statements or soften the commands.

\section{Conclusion}

This study is an application of systemic functional linguistics (SFL) to the comparison of four English translations of The Platform Sutra. Recognizing the dynamic relation between lexico-grammar and semantics, and that between text and context, the study relates lexico-grammatical choices of MOOD and MODALITY to speech functions of statements and proposals, and the image of the Chan master Huineng to the context of translation.

In providing information, more categorical indicative clauses are used by the two American translators, Heng Yin and Thomas Cleary, than that used by the Chinese translators Wong Mou-lam and Cheng Kuan. Similarly, more imperative clauses are adopted in issuing commands by Heng and Cleary than Wong and Cheng. Moreover, variation in the values of MODALITY can also be seen between these two groups of translators. While the American translators tend to use more high-valued modal expressions, the Chinese translators usually favour median- and low-valued MODALITY. Consequently, two types of image recreated of Huineng can be recognized: an authoritative and powerful Huineng versus a cautious and polite Huineng. An exploration of the possible textual and contextual factors influencing the process of translation leads us to the difference in the social distance between the translators and the target readers. The way Huineng preaches to the audience and talks to his disciples in the translation can be seen as a reflection of the method by which a translator tries to approach his target readers. Being aware of the huge cultural and ideological difference confronted in translating a traditional Eastern religious text into English, the Chinese translators are more cautious and tentative, which influences their linguistic choices and reconstruction of Huineng's image.

Translating is a process of making choices 'among a certain (and very often exactly definable) number of alternatives' (Levý 2012, 72). The study not only investigates the different linguistic choices in terms of MOOD and MODALITY made by different translators of the same source text, but also explores the semantic consequence of these choices. It also demonstrates that a text (including translated text) can be better understood by referring to its context. It is hoped that through this study, more attention can be drawn to the application of SFL to translations of religious texts which are usually assumed to be immune to extra-textual influences.

Competing intrests

The authors have no competing interests for this article.

Authors' contributions

HY conceived of the study, collected and analyzed the data, and drafted the manuscript. CW provided technical support, helped to draft the manuscript and critically revised it. Both authors read and approved the final manuscript. 
Authors' information

Hailing Yu is currently a PhD student in the Department of Linguistics, Macquarie University. Her research interests cover translation studies of classical Chinese literature, systemic functional linguistics, translation theories, and cross-cultural communication.

Dr. Canzong Wu is a Senior Lecturer in the Department of Linguistics, Macquarie University. He is specialized in systemic functional linguistics, the development of computational tools for multilingual grammatical reference resources, and translation studies.

\section{Acknowledgements}

Hailing Yu receives her scholarship from China Scholarship Council (CSC. 201408430081) and Macquarie University (CSC-MQ No. 2014136). Gratitude is given to these financial supports.

\section{Received: 4 December 2015 Accepted: 19 January 2016}

\section{Published online: 11 February 2016}

\section{References}

American Buddhist Temple. 1993. http://abtemple.org/mvtemple/content.php?c=7.

Biber, Douglas, Stig Johansson, Geoffrey Leech, Susan Conrad, and Edward Finegan. 1999. Grammar of Spoken and Written English. Harlow: Longman.

Brown, Penelope, and Stephen C. Levinson. 1987. Politeness: Some universals in language usage, vol. 4. Cambridge: Cambridge University Press.

Butler, Christopher S. 1988. Politeness and the semantics of modalised directives in English. In Linguistics in a systemic perspective, ed. James Benson, Michael Joseph Cummings, and William S. Greaves, 119-54. Amsterdam: John Benjamins Publishing

Butt, David. 2004. Working with Tenor. Sydney: Macquarie University CLSL.

Butt, David, Rhondda Fahey, Susan Feez, Sue Spinks, and Colin Yallop. 2006. Using Functional Grammar: An Explorer's Guide. Sydney: National Centre for English Language Teaching and Research, Macquarie University.

Bybee, JL, and Suzanne Fleischman. 1995. Modality in grammar and discourse: An introductory essay. In Modality in grammar and discourse, ed. J. L Bybee and Suzanne Fleischman, 1-14. Amsterdam/Philadelphia: John Benjamins Publishing.

Camiciottoli, Belinda Crawford. 2004. Interacting with the Audience: Modal Verbs in Cross-cultural Business Lectures. In English Modality in Perspective: Genre Analysis and Contrastive Studies, ed. Roberta Facchinetti and F. R Palmer, 27-43. Frankfurt: Peter Lang.

Cheng, Kuan. 2011. The Dharmic Treasure Altar-Sutra of the Sixth Patriarch. Taipei: Vairocana Pulishing Co., Ltd.

Cleary, Thomas. 1998. The Sutra of Hui-neng, grand master of Zen: with Hui-neng's commentary on the Diamond Sutra. Boston \& London: Shambhala Publications.

Coates, Jennifer. 1983. The semantics of the modal auxiliaries. London: Croom Helm.

Coates, Jennifer. 1987. Epistemic modality and spoken discourse. Transactions of the philological society 85(1):110-131

Coates, Jennifer. 1990. Modal meaning: the semantic pragmatic interface. Journal of Semantics 7:53-63.

Croft, William. 1994. Speech act classification, language typology and cognition. In Foundations of Speech Act Theory: Philosophical and Linquistic Perspectives, ed. S.L. Tsohatzidis, 460-477. London: Routledge.

Crompton, Peter. 1997. Hedging in academic writing: Some theoretical problems. English for Specific Purposes 16(4):271-287.

Dih, Ping Tsze. 1930. Preface. In Sutra Spoken by the Sixth Patriarch, Wei Lang, on the High Seat of the Gem of Law (Message from the East), ed. Wong Mou-Lam. Shanghai: Yu Ching Press.

Downes, William. 2011. Language and religion: a journey into the human mind. Cambridge: Cambridge University Press.

Eggins, Suzanne. 1994. An introduction to systemic functional grammar. In An introduction to systemic functional grammar.

Eggins, Suzanne, and Diana Slade. 1997. Analyzing Casual Conversation. London: Cassell.

Gao, Qiuping. 2012. Interpersonal functions of epistemic modality in Academic English Writing. Chinese Journal of Applied Linguistics 35(3):352-364.

Halliday, MAK. 1970. Functional diversity in language as seen from a consideration of modality and mood in English. Foundations of language 6(3):322-361.

Halliday, MAK, and R Hasan. 1989. Language, Context, and Text: Aspects of Language in a Social-semiotic Perspective. Melbourne: Deakin University.

Halliday, MAK, and Christian Matthiessen. 2004. An Introduction to Functional Grammar, Third edition. London: Arnold.

Halliday, MAK, and Edward McDonald. 2004. Metafunctional Profile of the Grammar of Chinese. In Language Typology: a functional perspective, ed. Alice Caffarel, J. R. Martin and Christian Matthiessen, 305-396. Amsterdam/Philadelphia: John Benjamins Publishing.

He, Agnes Weiyun. 1993. Exploring modality in institutional interactions: Cases from academic counselling encounters. Text 13(4):503-528.

Heng, Yin. 1977. The Sixth Patriarch's Dharma Jewel Platform Sutra. California: Sino-American Buddhist Association, Buddhist Text Translation Society.

Holmes, J. 1984. Hedging your bets and sitting on the fence: some evidence for hedges as support structures Te Reo 27:47-62.

Hsuan, Hua. 1977. Tripitaka Master Hua's Introduction. In The Sixth Patriarch's Dharma Jewel Platform Sutra, edited by Heng Yin, xv-xvi. California: Sino-American Buddhist Association, Buddhist Text Translation Society.

Hyland, Ken. 1994. Hedging in academic writing and EAF textbooks. English for specific purposes 13(3):239-256.

Hyland, Ken. 1996. Talking to the academy forms of hedging in science research articles. Written communication 13(2):251-281. 
Jorgensen, John. 2005. Inventing Hui-neng, the Sixth Patriarch: Hagiography and Biography in Early Ch'an, vol. 68. The Netherlands: Brill.

Ko, Ping-Yip. 1996. The History of "The Sutra of Hui-Neng" in English Versions Translations. In The Dharmalakshana Buddhist Institute Buddhist Journal IV.

Levý, Jiř́. 2012. Translation as a Decision Process. Scientia Traductionis 11:72-96.

Low, Sang-Thoi. 2010. A Prewliminary Study of Liuzu Tanjing: with a Focus on Cheng Kuan's Version. Master Master Thesis. Taipei: The Graduate Institute of Translation and Interpretation National Taiwan Normal University.

Lyons, John. 1977. Semantics. Cambridge, Eng: Cambridge University Press.

Maha-Vairocana Temple. 1991. http://abtemple.org/mvtemple/content.php?c=6.

Markkanen, Raija, and Hartmut Schröder. 1997. Hedging and discourse: Approaches to the analysis of a pragmatic phenomenon in academic texts, vol. 24. Berlin/New York: Walter de Gruyter.

Martin, JR, and PRR White. 2005. The language of evaluation: appraisal in English. Hampshire: Palgrave Macmillan.

Matthiessen, Christian. 1995. Lexicogrammatical Cartography: English Systems. Tokyo: International Language Sciences Publishers.

Matthiessen, Christian, and MAK Halliday. 2009. Systemic functional grammar: a first step into the theory.

Myers, Greg. 1989. The pragmatics of politeness in scientific articles. Applied linguistics 10(1):1-35.

Palmer, FR. 2001. Mood and modality, 2nd ed. Cambridge: Cambridge University Press.

Palmer, FR. 2003. Modality in English: Theoretical, descriptive and typological issues. In Modality in Contemporary English, ed. Roberta Facchinetti, Manfred Krug, and F.R. Palmer, 1-20. Berlin: Mouton de Gruyter.

Perkins, Michael R. 1983. Modal expressions in English / Michael R. Perkins. London: Frances Pinter.

Schlutter, Morten. 2007. Transmission and Enlightenment in Chan Buddhism Seen Through the Platform Sutra (Liuzu tanjing 六祖壇經). Chuang-Hwa Buddhist Journal no. 20:379-410.

Simon-Vandenbergen, Anne-Marie. 1996. Image-building through modality: The case of political interviews. Discourse \& Society 7(3): 389-415.

Simpson, Paul. 1990. Modality in literary-critical discourse. In The writing scholar: Studies in academic discourse, ed. Walter Nash, 63-94. London: Sage Publications.

Steiner, Erich. 1998. A register-based translation evaluation: an advertisement as a case in point. Target 10(2): 291-318. White, PRR. 2000. Dialogue and inter-subjectivity: reinterpreting the semantics of modality and hedging. In Dialogue analysis VII: Working with dialogue, ed. Malcolm Coulthard, Janet Cotterill and Frances Rock, 67-80. Tübingen: Niemeyer.

White, PRR. 2003. Beyond modality and hedging: A dialogic view of the language of intersubjective stance. TEXT 23(2):259-284.

Wong, Mou-Lam. 1930a. Sutra Spoken by the Sixth Patriarch, Wei Lang, on the High Seat of the Gem of Law (Message from the East). Shanghai: Yu Ching Press.

Wong, Mou-Lam. 1930b. Translator's preface. In Sutra Spoken by the Sxith Patriarch (Wei Lang) on the High Seat of the Gem of Law (Message from the East), ed. Wong Mou-Lam. Shanghai: The Pure Karma Buddhist Association.

Wu, Canzhong. 2000. Modelling Linguistic Resources: A Systemic Functional Approach. PhD. Sydney: Macquarie University.

Yu, Hailing. 2011. Figurative Expressions in Tan Jing and Their Translations (tanjing zhong biyu shouduan de shiyong ji yingyi, 《坛经》中比喻手段的使用及英译). Journal of Hotan Teachers College 30(3):65-67.

\section{Submit your manuscript to a SpringerOpen ${ }^{\circ}$ journal and benefit from:}

- Convenient online submission

- Rigorous peer review

- Immediate publication on acceptance

- Open access: articles freely available online

- High visibility within the field

- Retaining the copyright to your article 